\title{
The Effect of Happiness Program on the Hope of Addicts Experiencing Drug Withdrawal at Zahedan Psychiatric Hospital: A Quasi-Experimental Study
}

\author{
Fatemeh Pirkamali ${ }^{1}$, Ali Navidian ${ }^{2}$, Nasrin Rezaee $^{3}$
}

\begin{abstract}
Background \& Aims: Drug addiction is one of the serious problems that has caused many concerns in society. In Iran, addiction is highly prevalent among different age groups. Due to diagnostic and reporting conditions, accurate statistics about the number of addicts are not available. However, the population of drug addicts seems to be increasing every year, and this is a serious warning to society. A large number of drug users refer to drug treatment centers every year, but after a while, they tend to use drugs again, which is one of the challenges of society. According to the results of some studies, there is a significant relationship between hope and the cleansing period of drug addicts. Since hope can be a fundamental and motivating factor in drug withdrawal and may play an important role in all stages of drug withdrawal, from action to continuing withdrawal and recovery, it seems that implementing interventions that can raise hope in addicts experiencing withdrawal is necessary for drug withdrawal and its continuation. Therefore, considering that happiness-based programs can increase life expectancy in people, this study aimed to determine the effect of the happiness program on the hope of addicts experiencing withdrawal at the psychiatric center of Zahedan.

Materials \& Methods: This is a quasi-experimental study. Men aged 18 to 50 years who were admitted to Zahedan Psychiatric Hospital in autumn and winter of 2020 for drug withdrawal comprised the study population. The samples included 92 addicted men. They were selected based on convenience sampling procedure and were randomly divided into intervention $(n=46)$ and control $(n=46)$ groups. Inclusion criteria were no physical symptoms of withdrawal such as pain and restlessness, no psychotic disorder associated with drug abuse, no participation in another counseling program at the same time, and no other addicted family members. More than one session absenteeism and hospital discharge prior to completion of the program were exclusion criteria. In this study, first the control group and then the intervention group entered the study based on non-random sampling procedure. This method was used to prevent the transfer of information in groups. Data collection tools in this study included demographic information form and Miller Hope Scale. This questionnaire was conducted in two stages; pre-test and posttest which was conducted two months later. In the intervention group, eight sessions of the Fordyce Happiness Program were performed every other day. The content of the sessions was prepared based on the Fordyce training program. The Fordyce Happiness Program is a program designed to increase people's happiness and includes eight cognitive components and six behavioral components. The study was conducted based on six Fordyce behavioral components that included components such as increasing activity, increasing social interaction, strengthening close relationships, fostering social personality, creativity, engaging in meaningful works, and self-worth. Data were analyzed using independent $t$-test, paired t-test, chi-square, and ANCOVA in SPSS 16. The study was statistically significant at $\mathrm{P}<0.05$.
\end{abstract}

\footnotetext{
1. MS in Psychiatric Nursing, School of Nursing and Midwifery, Zahedan University of Medical Sciences, Zahedan, Iran

2. Department of Psychiatric Nursing, School of Nursing and Midwifery, Community Nursing Research Center, Zahedan University of Medical Sciences, Zahedan, Iran

3. Department of Psychiatric Nursing, School of Nursing and Midwifery, Community Nursing Research Center, Zahedan University of Medical Sciences, Zahedan, Iran (Corresponding Author) Tel: 09153411705 E-mail: rezaee_n@zaums.ac.ir
} 
Results: The results of the Shapiro-Wilk test showed normal distribution of data. Therefore, parametric tests were used in this study. The findings showed that most addicts experiencing drug withdrawal were married and mostly used a combination of opium derivatives. The mean hope scores of these addicts before the implementation of the Fordyce happiness program in the intervention and control groups were 139.15 \pm 54.06 and $179.22 \pm 58.30$, respectively, and then changed to $187.25 \pm 8.99$ and $172.16 \pm 45.50$. Independent t-test showed that the mean hope scores of addicts both before $(\mathrm{P}=0.001)$ and after $(\mathrm{P}=0.002)$ Fordyce happiness program were significantly different between the intervention and control groups. In addition, paired t-test showed that the mean scores of hope in the intervention group increased significantly $(\mathrm{P}=0.001)$ and decreased significantly in the control group $(\mathrm{P}=0.005)$. The results of ANCOVA for controlling the significant effect of pre-test scores and duration of addiction showed that the mean scores of hope among addicts experiencing drug withdrawal were significantly different between the two groups after the intervention $(\mathrm{P}=0.001)$.

Conclusion: The present study was conducted to determine the effect of happiness programs on the hope of addicts admitted to Psychiatric Hospital for drug withdrawal. The results of ANCOVA for controlling the significant effect of pre-test scores and duration of addiction showed a statistically significant difference between the mean hope scores of addicts in both groups after the intervention. In fact, the findings showed that implementing the Fordyce Happiness Program can raise the hopes of addicts experiencing drug withdrawal. Therefore, considering that hope has a motivating role in people and is an important factor in maintaining and continuing drug cleansing, happiness programs such as the Fordyce Happiness Program can affect addicts' hopes, which is an important factor in preventing relapse. Therefore, it is suggested that the behavioral component of Fordyce Happiness, which can be easily implemented by nurses, be implemented in drug treatment centers, such as wards and drug treatment camps. Not only can the happiness program be included in the daily routine of addicts experiencing withdrawal, but also, it can be continued after discharge from medical centers. One of the limitations of the present study is the generalization of results to addicts with a history of mental illness. This study was also performed on addicts who were hospitalized in a psychiatric hospital for drug withdrawal. Therefore, generalizing the results to addicts who refer to drug treatment camps to understand addiction should be done with caution.

Keywords: Addiction, Hope, Happiness, Fordyce

\section{Conflict of Interest: No}

How to Cite: Pirkamali F, Navidian A, Rezaee N. The Effect of Happiness Program on the Hope of Addicts Experiencing Drug Withdrawal at Zahedan Psychiatric Hospital: A Quasi-Experimental Study. Iran Journal of Nursing. 2021; 34(130):38-47.

Received: 10 March 2021

Accepted: 12 Jun 2021 


\title{
تأثير اجراى بر نامه شادكامى بر اميد معتادان در حال ترك مراجعه كننده به بيمارستان روانيزشكى شهر زاهدان: يك مطالعه نيمه تجربى
}

\author{
فاطمه يير كمالى '، على نويديان 'ّ نسرين رضائى
}

جكيده

زمينه و هدف: برخى معتادان يس از ترى مواد، مجددا" كرايش به مصرف مواد بيدا مى كنند. برنامهاى مبتنى بر روشهاى شادكامى مىتواند منجر به



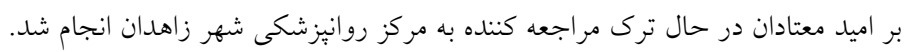

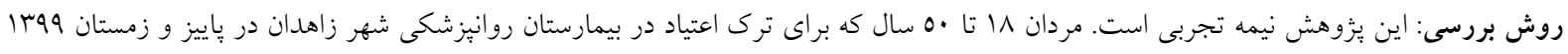

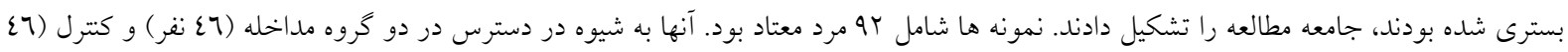

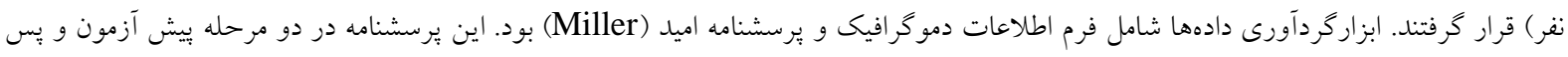

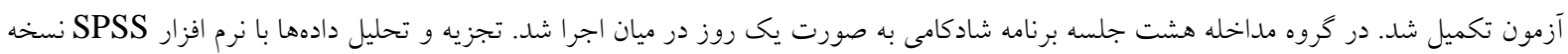

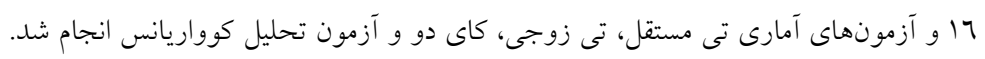

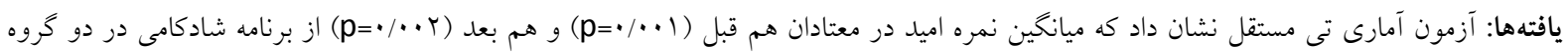
مداخله و كنترل تفاوت معنىدارى داشته است. همجنين آزمون تى زوجى نشان داد كه ميانخين نمره اميد در كروه مداخله به طور معنىدارى افزايش

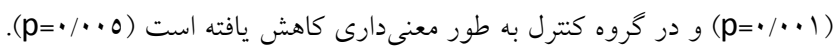

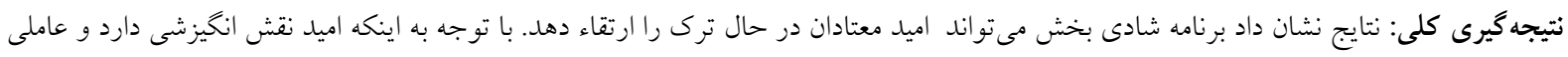
مهم در حفظ و تداوم دورى از مصرف مواد است، مىتوان با اجراى برنامههاى شادى بخش هميجون برنامهاى مبتنى بر شادكامى فوردايس بر اميد

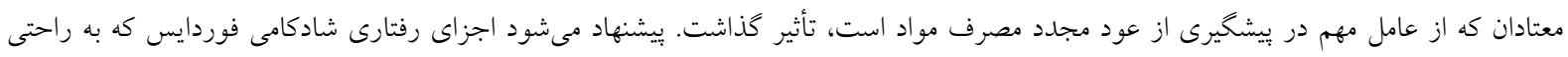

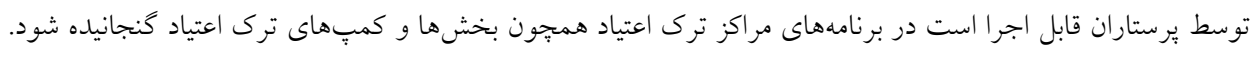

كليل وازهها: اعتياد، اميد، شاد كامى، فوردايس تعارض منافع: وجود ندارد. تاريخ دريافت: • 99/T/Y

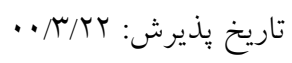

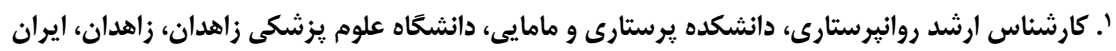

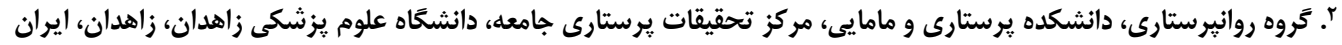

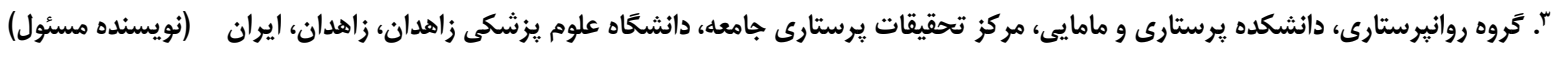


زندكى در وى ارتقاء نيابد با مشكل اعتياد و عود مجدد آن



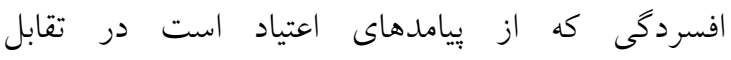

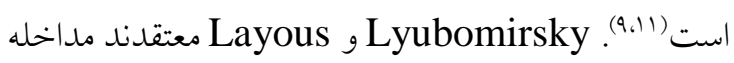
هاى مثبت گرا با افزايش هيجان مثبت و افكار مثبت سبب كاهش افسردكى در افراد مىشود (ז'). نتايج مطالعه فيروزه

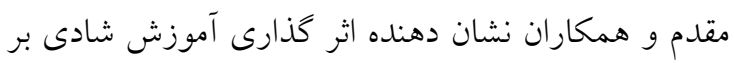

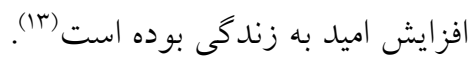
يافتهاى مطالعه زند نشان داد شادكامى از متغيرهاى مشخص كننده سلامت روان در افراد معتاد است(1). شادكامى را حالتى حاكى بر ابراز هيجانات مثبت،

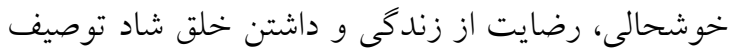

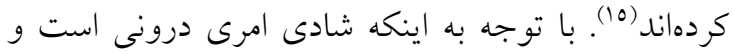

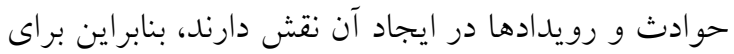

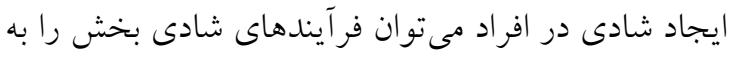
آنان آموزش داد. برنامه شادكامى Fordyce عـ الصل دارد؛ از اين تعداد هشت مورد شناختى و شش مورد رفتارى

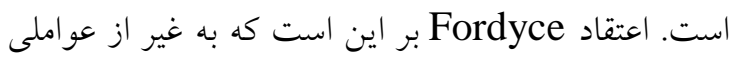

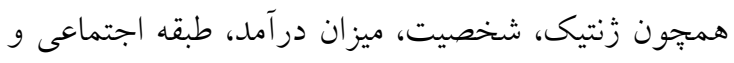

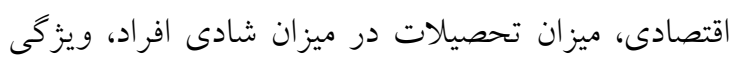

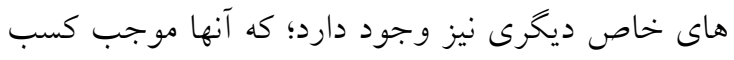

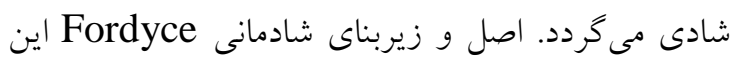
است كه اكر شخص بخواهد مىتواند همانند افراد شاد، شاد باشد (10-IV) مرور مطالعات نشان داد برخى از افراد معتاد پِ از ترى مو اد، مجدد در فاصله اندكى پيس از ترك با دلايل مختلف

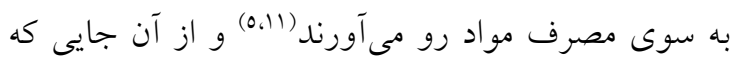
اميد مىتواند عامل بنيادى و انخيزشى ترى اعتياد به مواد باشد و در همه مر احل ترك از اقدام تا تداوم ترك و بهبودى

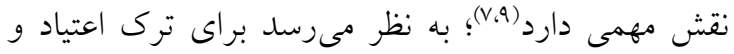
تداوم آن اجراى مداخلاتى كه بتواند اميد را در فرد ارتقاء دهد ضرورى است. بنابر اين با توجه به اين كه برنامههاى

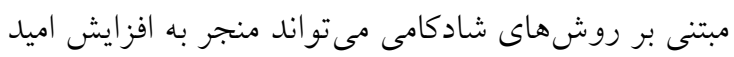

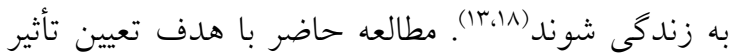

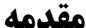

اعتياد از مشكلات جدى و اساسى است كه باعث نخرانى

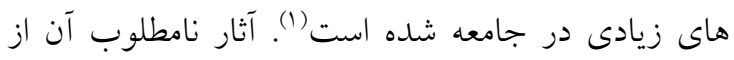
جمله بحرانهاى سلامت در دوران معاصر به شمار مى رئ

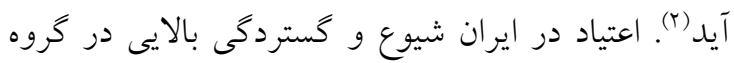

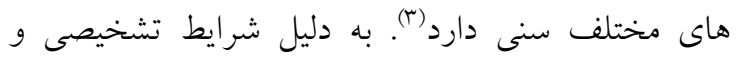

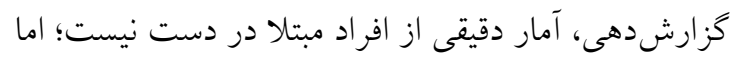

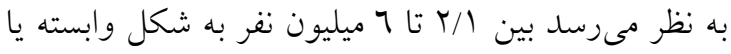
تفننى، مواد مصرف مى كنند كه هر با سال تعداد آنان دو

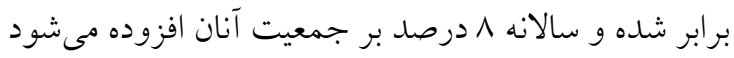

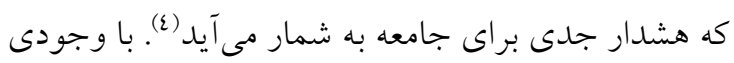
كه سالانه تعداد زيادى از سوء مصرف كنندگان مواد به بهان

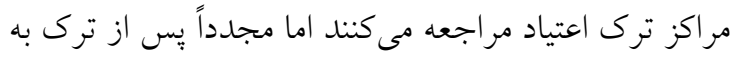
سمت مصرف مواد كرايش بيدا مىكنند و اين يكى از معضلات ييش روى جامعه به شما مىرود (0).

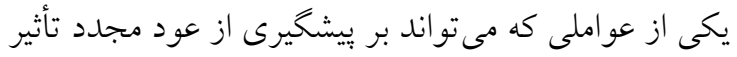

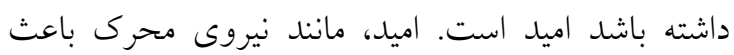
حركت فرد براى بهتر شدن، كسب موفقيت و رسيدن به اهداف است. در حقيقت اميد باعث مىشود فرد براى آينده

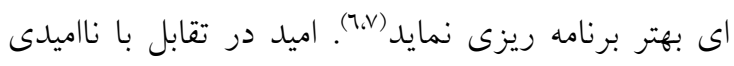

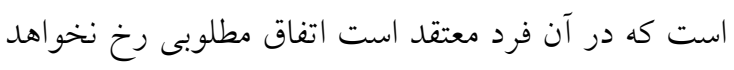
داد و ييامدهاى ناراحت كنندهاى ايجاد خواهد كرد مرد. Aaron Beck


شود؛ اما اميد همسو با خوش بينى، احساس كنترل بر رفتار

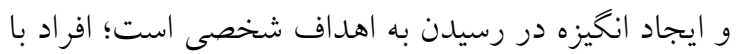
اميدوارى بايين انخيزه و نيروى محركه براى رسيدن به

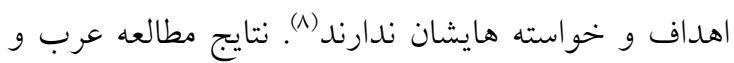
همكاران نشان داد ارتباط معنى دارى بين اميد با مدت زمان

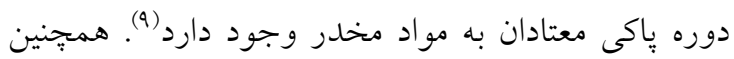
نتايج مطالعه دهقانى و خدابخشى نشان داد اميد سبب مورد

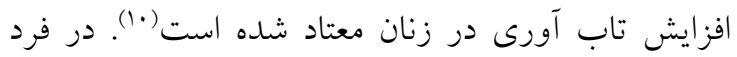
مبتلا به اعتياد اميد پِيين است و براى تغيير شر ايط زندكى نيازمند افزايش اميد به زندكى است و تا هنخامى كه اميد به به بهين 
وضعيت تأهل، طول مدت اعتياد، تعداد دفعات ترك و نوع ماده مصرفى بود. بخش دوم، ير سشنامه اميد ميلر (Miller)

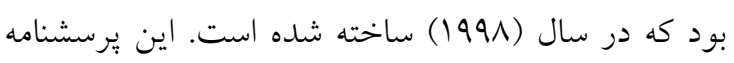

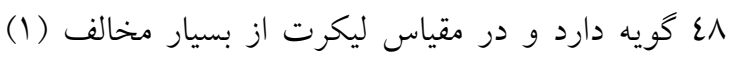

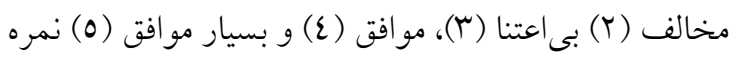

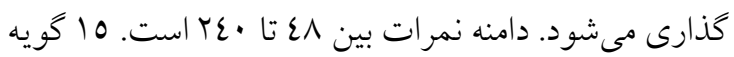

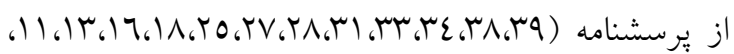
عـ، عV،

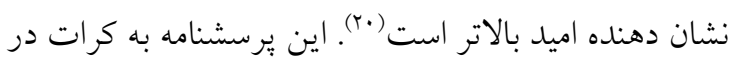
ايران استفاده شده است. در يزوهش محمد زاده و همكاران

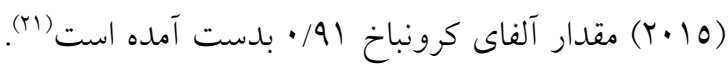
در اين مطالعه نيز ثبات درونى آن به روش آلفاى كرونباخ ع ع/ • محاسبه شد. ساختار جلسات مبتنى بر برنامه آموزشى Fordyce تهيه

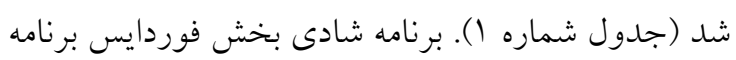
اى است كه براى افزايش شادكامى افراد ارائه شده است. اين برنامه هشت جزء شناختى و شش جزء ائ رفتارى دارئ دارد.

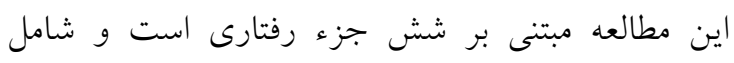

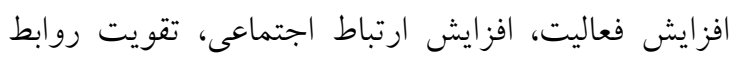

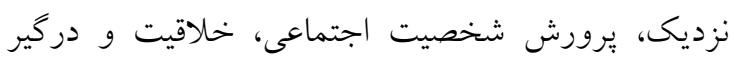
شدن در كارهاى ثرمعنا و خود بودن است (10.11).
برنامه شادكامى بر اميد معتادان در حال ترى مراجعه كننده به مركز روانيزشكى شهر زاهدان انجام كرفت.

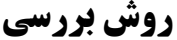

اين مطالعه، يزوهشى نيمه تجربى است. مردان •0-1 1 سال

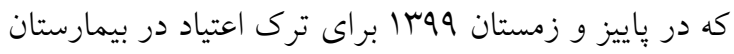
روانيزشكى شهر زاهدان بسترى شده بودند، جامعه مطالعه را تشكيل دادند. نمونه گيرى به شيوه در دسترس انجام شد.

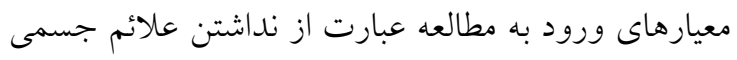
ترك اعتياد مثل درد و بىقرارى، نداشتن اختلال سايكوتيك

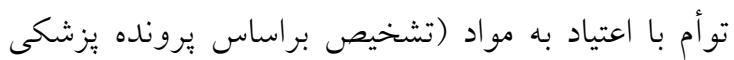


همزمان و وجود نداشتن عضو معتاد ديخرى در خانواده

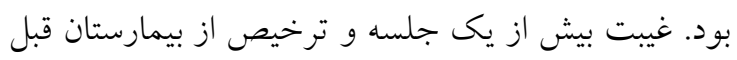

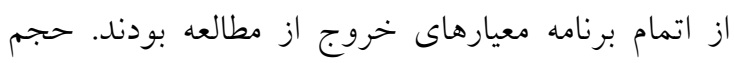

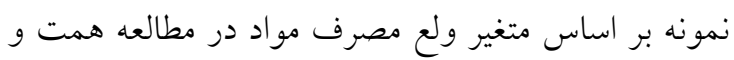

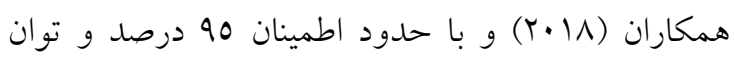



$$
\text { كرديد (19) مون المان }
$$

ابزارگردآورى اطلاعات شامل دو بخش بود. بخش اول

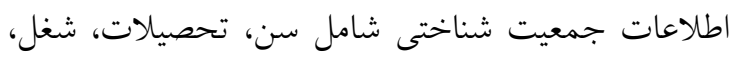

جدول شماره ا: محتواى جلسات برنامه شادكامى بر اميد معتادان در حال ترك بسترى در بيمارستان روانيزشكى شهر زاهدان در سال 11999

\begin{tabular}{|c|c|c|}
\hline جزء رفتارى فوردايس & 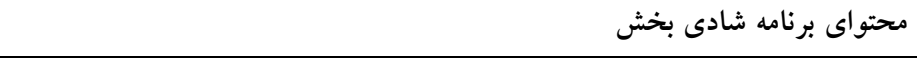 & جلسه \\
\hline انجام فعاليت، ارتباط اجتماعى إنى & - خوشامدكويى (معرفى اعضا) & اول \\
\hline \multirow[t]{3}{*}{ دركيربودن دركارهاى بر معنا } & - توضيح ييرامون مداخله و قوانين (رعايت نوبت/ دشنام ندادن به يكديخر) & \\
\hline & - انجام فعاليت ورزشى (مثل توب بازى/طناب بازى/ و ...) & \\
\hline & - در پيايان جلسه آموزش وانجام تن آرامى & \\
\hline 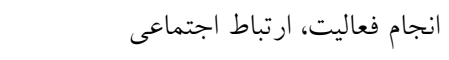 & - خوشامدكويى & دوم \\
\hline دركيربودن دركارهاى ير معنا & - انجام يك بازى گروهى مثل منج (دو گروه ع نفره) & \\
\hline خلاقيت & 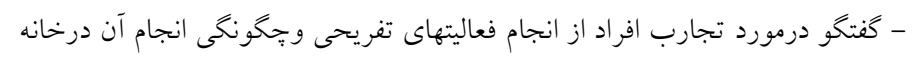 & \\
\hline \multirow[t]{2}{*}{ دركيربودن دركارهاى ير معنا و خود بودن } & (كَفتكو در مورد اينكه جهه فعاليتى را مىتوان در خانه انجام داد) & \\
\hline & - -در بايان جلسه آموزش وانجام تن آرامى & \\
\hline 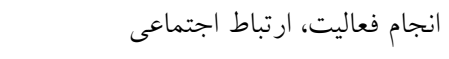 & 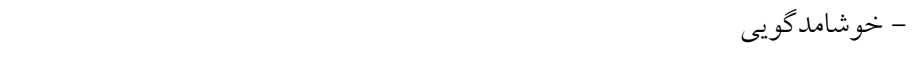 & سوم \\
\hline درخيربودن دركارهاى ير معنا & - باز كو كردن خاطرات خوشايند و تأثير كذار بر ترك مواد (توسط اعضا) & \\
\hline خلاقيت و & - لطيفه كويى - & \\
\hline
\end{tabular}




\begin{tabular}{|c|c|}
\hline دركيربودن دركارهاى ير معناو خود بودن & 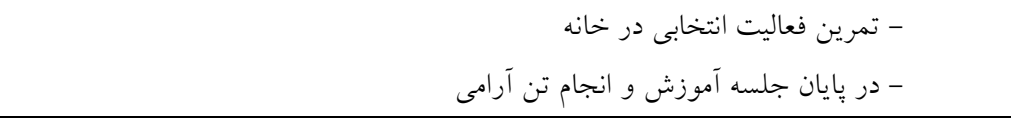 \\
\hline انجام فعاليت، ارتباط اجتماعى & 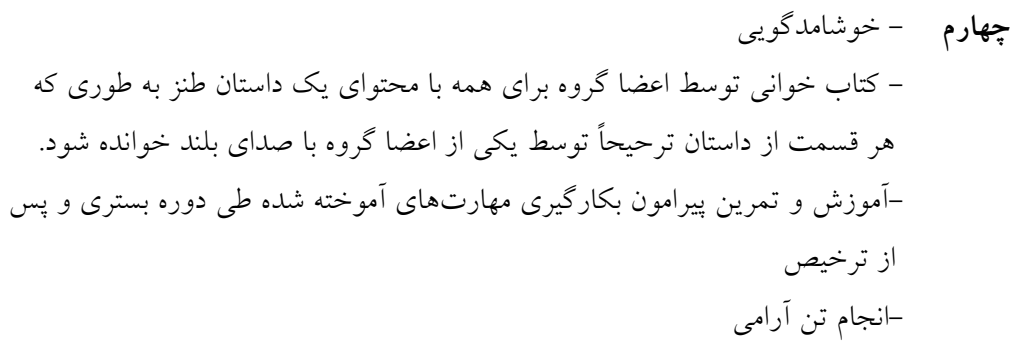 \\
\hline
\end{tabular}

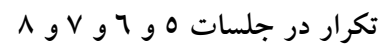

آمد تا جلسات براى آنان نيز تشكيل شود. ولى به علت همزمانى با بيمارى كويد 19 تعداد اندكى (بانفر) شركت كردند. اين مطالعه در كميته اخلاق دانشخاه علوم يزشكى زاهدان با كد اخلاق IR.ZAUMS.REC.1399.095 به ثبت رسيد. ملاحظات اخلاقى شامل كسب رضايت آكاهانه كتبى، اطمينان از محرمانه بودن اطلاعات و آزاد بودن افراد در شركت يا شركت نكردن در هر مرحلهاى از مطالعه، بوده

آناليز دادهها با نرم افزار SPSS نسخه 17 و آزمونهاى آمارى تى مستقل، تى زوجى، كاى دو و آزمون تحليل Pوواريانس انجام شد. سطح معنىدارى در اين مطالعه 0.05> از نظر آمارى معنىدار بود. نتايج آزمون شاييرو ويلك نشان داد كه دادهها از توزيع نرمال برخوردار هستند. بنابراين از آزمونهاى يارامتريك در اين مطالعه استفاده شد.

\section{يافتهها}

مشخصات كروهها در جدول شماره Y ارائه شد. يافتهها

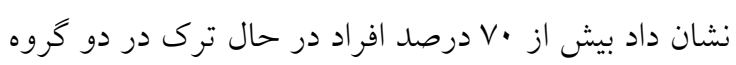

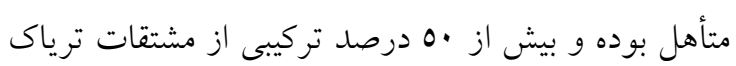

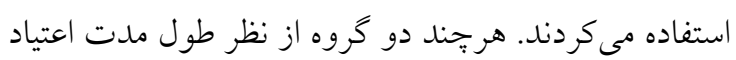
همخن نبودند و تفاوت معنى دارى بين دو گروه وجو داشت

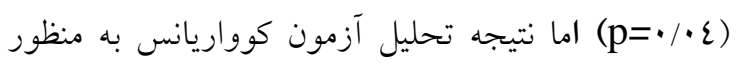
كتترل اثر معنى دارى طول مدت اعتياد نشان داد (جدول ع)،

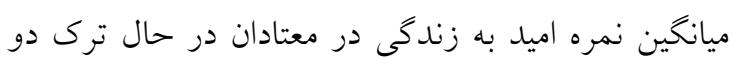
كروه هِ يس از مداخله تفاوت آمارى معنىدار دارد $(\mathrm{p}=\cdot / \cdot \cdot)$


(IR.ZAUMS.REC.1399.095) براى هماهنگى با. (IR.) مسئولين بيمارستان به بخشهاى ترى اعتياد مراجعه شد. بعد از معرفى بززوهش و دريافت رضايت نامه كتبى، افرادى كه معيارهاى ورود به مطالعه را داشتند انتخاب شدند. براى برى افراد گروه مداخله در گروههاى Y I-1 نفره برنامه مداخله شادكامى طى هشت جلسه در مدت •9- •7 دقيقه اجرا شد. اين روند تا زمانى كه حجم نمونه كامل شد ادامه يافت. مداخله يك روز در ميان بود. برنامه در فضاى باز و محوطه

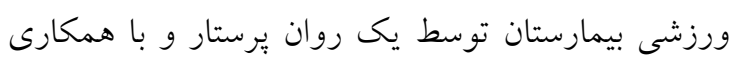
روانشناس بخش انجام شد. براى گرووه مداخله يس از اتمام

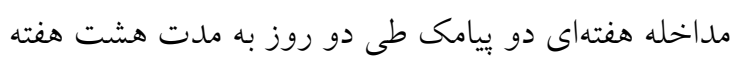
توسط يزوهشخر به بيمار ارسال شد؛ محتواى بيامكها تأكيد بر انجام برخى فعاليتهاى تفريحى كه در طول برنامه

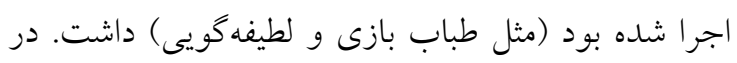
مرحله يس آزمون بِسشنامه اميد دو ماه بعد از اتمام مداخله

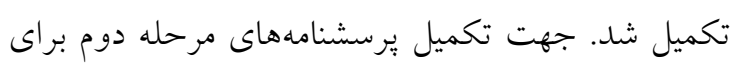
هر دو گروه با نمونهها تماس گرفته شد و در محل بيمارستان و يا مراجعه به درب منزل بيمار تكميل شد. در اين مطالعه ابتدا گروه كنترل و سبس گروه مداخله وارد مطالعه شدند (اين شيوه به دليل جلو گيرى از انتقال

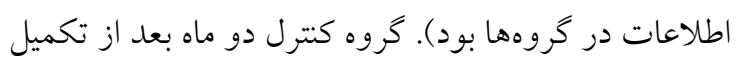

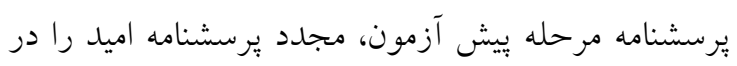

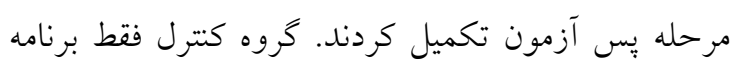
معمول بيمارستان را دريافت كرد. به جهت ملاحظات

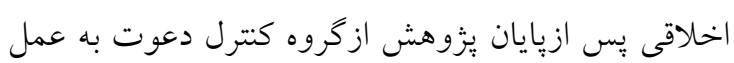


جدول شماره ץ: مقايسه مشخصات دموكَ, افيكى معتادان در حال ترك بسترى در بيمارستان روانيزشكى شهر زاهدان در تروه كنترل و مداخله

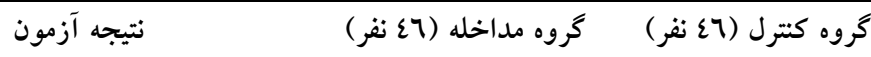
متغير

$($ Mean \pm SD)

$($ Mean \pm SD)


دارى افزايش (1)

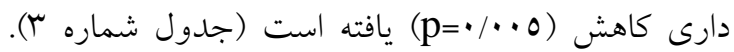
نتيجه تحليل آزمون كوواريانس به منظور كنترل اثر معنى دارى نمرات ييش آزمون و طول مدت اعتياد نشان داد كه ميانگين نمره اميد در معتادان در حال ترك دو گروه يس از



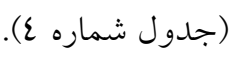

مى دهد كه ميانخين نمره اميد در گروه مداخله بطور معنى

ميانخين نمره اميد در معتادان در حال ترك قبل از اجراى برنامه شادكامى فوردايس در كروه مداخله و كترل به به ترتيب 10/.7

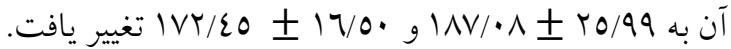
آزمون آمارى تى مستقل نشان داد كه ميانخين نمره اميد در

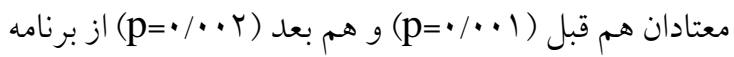
شادكامى فوردايس در دو گروه مداخله و كتترل تفاوت معنى دارى داشته است. همجنين آزمونهاى تى زوج نشان

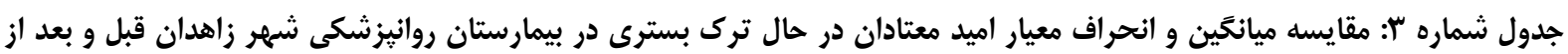
برنامه آموزش شادكامى در تَروه مداخله و كنترل

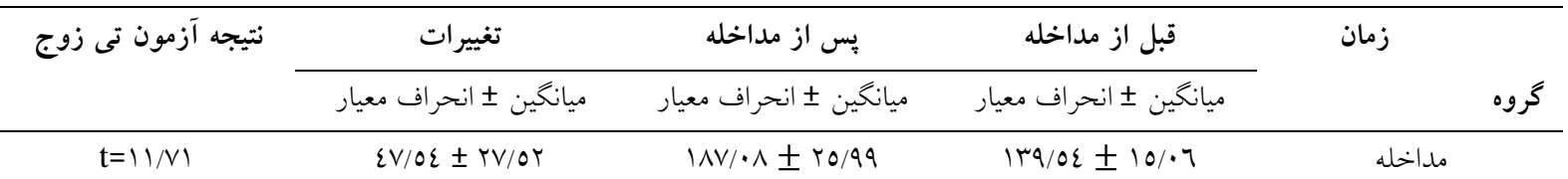
$\mathrm{df}=\{0 \quad \mathrm{P}=\cdot / \cdot \cdot 1$

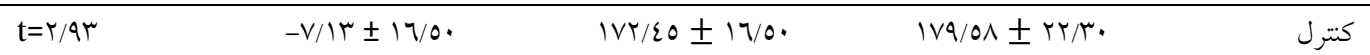
$\mathrm{df}=\varepsilon 0 \quad \mathrm{P}=. / \cdots 0$ $t=11 / 00$

$\mathrm{df}=q . \quad \mathrm{P}=\cdot / \cdot \cdot$ $\mathrm{df}=q \cdot \mathrm{P}=\cdot / \cdots r$
نتيجه آزمون تى مستقل

$\mathrm{df}=q . \quad \mathrm{P}=\cdot / \cdot \cdot$ 
جدول شماره ع: نتايج تحليل كواريانس مربوط به ميانكَين نمره اميد در معتادان در حال ترك بعد از برنامه شادكامى با كنترل اثر بيش آزمون و طول مدت اعتياد

\begin{tabular}{|c|c|c|c|c|c|c|c|}
\hline توان آزمون & اندازه تأثير & سطح معنىدارى & $F$ & ميانخين مجذورات & درجه آزادى & مجموع مجذورات & منبع تغييرات \\
\hline$\cdot / 9 V$ & .110 & $\% \cdot 1$ & $17 / \cdots$ & $77 r \cdot / 27$ & 1 & $77 \pi \cdot / 27$ & يِيش آزمون \\
\hline$\cdot / \cdot 7$ & $\cdot / \cdots 1$ & $\cdot / v \varepsilon$ &.$/ 1$ & $\varepsilon r / 0 \varepsilon$ & 1 & $\varepsilon r / 0 \varepsilon$ & طول اعتياد \\
\hline \multirow[t]{3}{*}{.$/ 99$} & 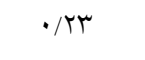 & $\cdot / \cdots 1$ & $r V / 7 q$ & IIEVV/AT & 1 & UEVV/AT & كروه \\
\hline & & & & $\varepsilon \mid \varepsilon / \mu V$ & $\Lambda$ & M $2 \varepsilon 70 / T V$ & ميزان خطا \\
\hline & & & & & 94 & $r \cdot r \mid r \cdot r$ & جمع \\
\hline
\end{tabular}

منجر به كاهش افسردگى و افزايش اميد آنان مىشود (TT). هم:جنين يافتهاى مطالعهاى در شهر قزوين نشان داد براى درمان مشكلات روانشناختى معتادان تحت درمان متادون

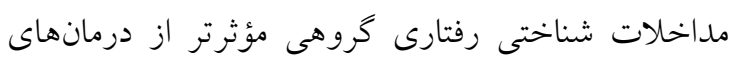
وجودى بوده است (TV).

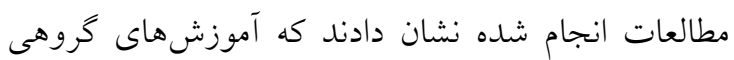

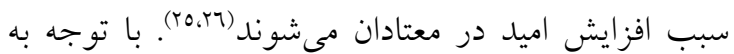
اينكه افسردگى نقطه مقابل اميد به زندكى است و نتايج مطالعاتى كه نشان دادند مداخلات شناختى رفتارى در بيماران در حال ترى منجر به كاهش خلق منفى آنان شده

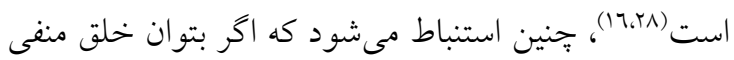

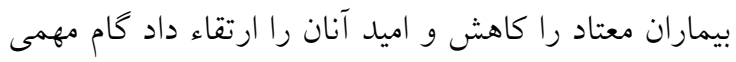



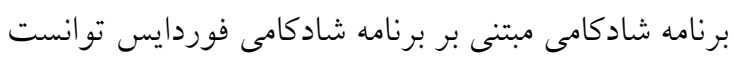

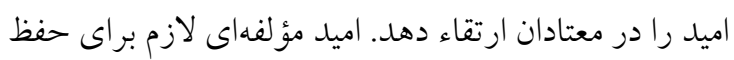

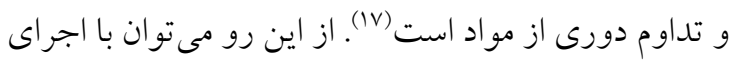

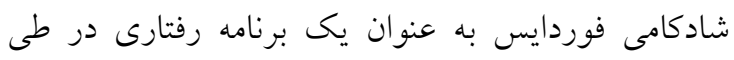

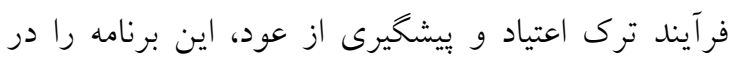

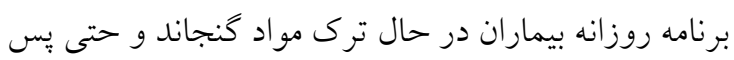
از ترخيص از مر اكز درمانى از آن استفاده كرد.


سابقه بيمارى روانى است در اين مطالعه فقط بيمارانى كه تنها مشكل اعتياد داشتند در يزوهش شركت كردند. هم:جنين به دليلى كه مطالعه حاضر بر روى معتادانى كه براى ترى اعتياد در بيمارستان روانيزشكى بسترى بودند انجام شده بود، بنابراين تعميم نتايج به معتادانى كه براى

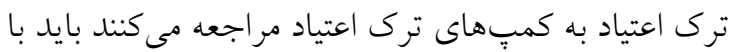

\section{بحث و نتيجه كيرى} نتايج يزوهش حاضر نشيجه يرى نشان دهنده تأثير معنى دار برنامه مبتنى

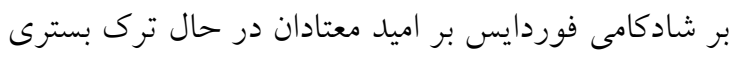
بود. اين يافته با برخى يافتهاى مطالعات قبلى همسو بود.

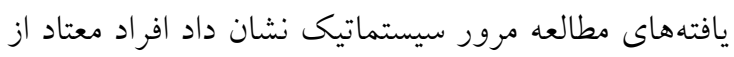

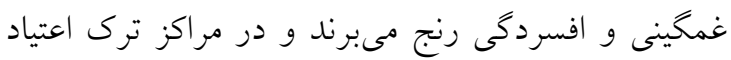

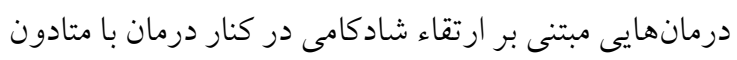


افسرده ناميد هستند و متغيرهاى ميانجى مىتوانند در كاهش افسردگى و ارتقاء اميد نقش ايفا كنند(Yr). نتايج مطالعه ثروت يارى و همكاران نشان داد افسردگى و ناميدى نقش مهمى در ييش بينى آمادكى افراد به سمت

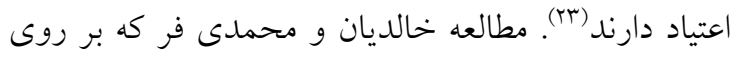
دانش آموزان در حال ترك انجام شد بود، نشان داد درمان كروهى شناختى رفتارى بر اميد به زندخى معتادان مؤثر بوده

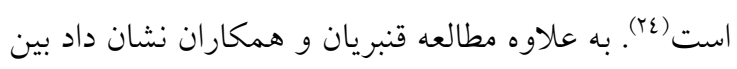

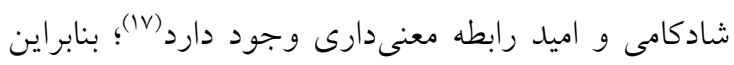

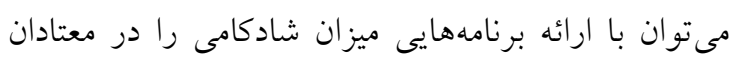
ارتقاء داد (17). مطالعه حاضر بصورت گروهى انجام شد. در راستاى اثر بخشى مداخلات گروهى مى توان اذعان داشت مداخلات كروهى در معتادان در حال ترى به نظر مؤثرتر از ساير

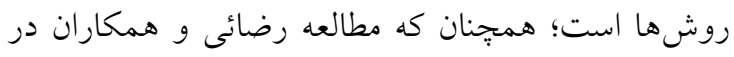

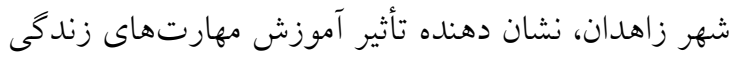

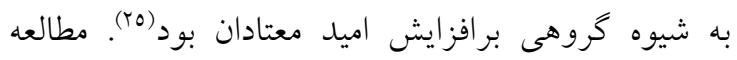

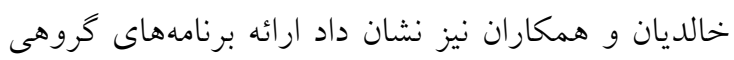
براى معتادان در حال ترى شهر قراوه در استان كردستان 


$$
\begin{aligned}
& \text { بازه زمانى طولانى تر براى درى بهتر از اثر بخشى مطالعه و } \\
& \text { احتمال بيشخيرى از عود انجام شود. } \\
& \text { تعارض منافع: هيجگگ نه تعارض منافعى توسط نويسندكان } \\
& \text { بيان نشده است. } \\
& \text { تقدير و تشكر } \\
& \text { از ترستاران بخش ترك اعتياد بيمارستان روانيزشكى شهر لئر }
\end{aligned}
$$

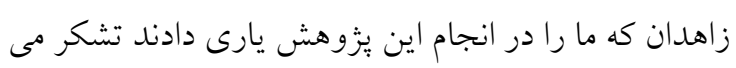

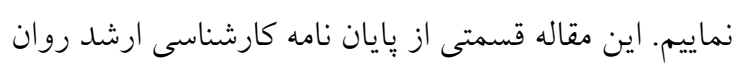

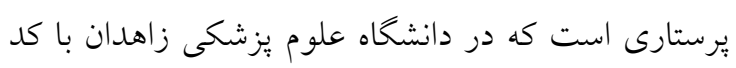

$$
\begin{aligned}
& \text { طرح ع و 9 به ثبت رسيده است. }
\end{aligned}
$$

\section{References}

1- Jha D, Singh R. SMARTS: the social media-based addiction recovery and intervention targeting server. Bioinformatics. 2020;36(6):1970-2.

2- Firoozeh M, Takfallah L, Mohammadi-Semnani S, Jahan E, Emami A. The evaluation of personality disorders among drug abusers. Medical Science Journal of Islamic Azad UnivesityTehran Medical Branch. 2012;22(2):152-6. [Persian]

3 - Rahmati A, Zeraat Herfeh F, Hosseini SO. Effective factors in first drug use experience among male and female addicts: a qualitative study. Int J High Risk Behav Addic. 2018;7(4):e66547.

4 Naghibi SA, Azizpoor M, Ashari S, Hosseini SH, Alizadeh A. The study of the relation between suicidal thoughts and religious belief in patients under methadone maintenance treatment (MMT) of Sari in 2013. Religion \& Health. 2014;2(1):1-8. [Persian]

5- Khammarnia M, Peyvand M. The reasons of return to drug addiction and suggested solutions among the people referring to rehabilitation centers: A Qualitative Study. Journal of Rafsanjan University of Medical Sciences. 2018;17(6):523-38. [Persian]

6- Rahimi Pordanjani T, Mohamadzade Ebrahimi A, Sabour Z. On the Effectiveness of HopeOriented Psychotherapy in Motivation for Treatment among Drug Dependent Individuals. Scientific Quarterly Research on Addiction. 2016;10(39):129-45. [Persian]

7- Bradshaw SD, Shumway ST, Wang EW, Harris KS. Addiction and the mediation of hope on craving, readiness, and coping. J Group Addic Recov. 2014;9(4):294-312.

8- Schrank B, Woppmann A, Sibitz I, Lauber C. Development and validation of an integrative scale to assess hope. Health expectations. 2011 (4):417-28.

9- Arab A. The Relationship of Life Expectancy, Attitude towards Delinquent Behavior, and Experience of Drug Abuse among Male Senior High School Students of Shirabad and Downtown of Zahedan. Journal of Educational Psychology Studies. 2017;14(28):149-68. [Persian]

10- Dehghani Z, Khodabakhshi-koolaee A. Effectiveness of group hope therapy on quality of life and resilience in addicted women. $J$ Educ Community Health. 2017;4(1):28-34. [Persian]

11- Mohammadi Pashaky M, Yaghoubi AA, Mahmoodi Molaee AA, Abbasi Esfajir A. The effect of training life expectancy and coping styles on negative emotions of cardiac surgical patients' mental health. Journal of Nursing and Midwifery Sciences. 2014;1(2):1-7. [Persian]

12- Lyubomirsky S, Layous K. How do simple positive activities increase well-being? Current Direc Psycholog Sci. 2013;22(1):57-62. 
13- Firozeh Moghadam S, Borjali A, Sohrabi F. The efficiency of happiness training to increase the hope in elderly people. Iranian Journal of Ageing. 2014;8(4):67-72. [Persian]

14- Zand A, Shams J, Shakeri NH, Chatr-Zarrin F. The relationship between well-being and substance abuse relapse. Research in Medicine. 2017;41(1):31-6. [Persian]

15- Rabiei L, Mazaheri MA, Masoudi R, Hasheminia SA. Fordyce happiness program and postpartum depression. Journal of research in medical sciences: the official journal of Isfahan University of Medical Sciences. 2014;19(3):251-6. [Persian]

16- Mohammadi M, Kazeminia M, Abdoli N, Khaledipaveh B, Shohaimi S, Salari N, Hosseinian-Far M. The effect of methadone on depression among addicts: a systematic review and meta-analysis. Health Quality Life Outcomes. 2020;18(1):1-2.

17- Ghanbarian M, Parmouz M, Rajabzadeh Z. The relationship between the happiness and life expectancy among the students of medical sciences in Behbahan city. Journal of Fundamentals of Mental Health. 2016;18(Special Issue):553-6. [Persian]

18- Fordyce MW. A program to increase happiness: further studies. J Couns Psychol. 1983;30(4):483.

19- Hemmat A, Hemmat J, Pirzeh R, Dadashi M. The Effectiveness of Group Therapy Based on Acceptance and Commitment to Reduce Obsessive-Compulsive Use of Substance, Anxiety and Depression of Addicts under Methadone Treatment. Journal of Advances in Medical and Biomedical Research. 2018;26(117):109-25. [Persian]

20- Miller JF. Development of an instrument to measure hope. Nurs Res. 1988; 37(1):6-10.

21- Mohammadzadeh M. The Relationship of Resilience and Emotional Regulation with Life Expectancy among Soldiers. Military Caring Sciences Journal. 2019;6(3):198-206. [Persian]

22- Kaleta K, Mróz J. The relationship between basic hope and depression: forgiveness as a mediator. Psychiatric Quarterly. 2020;91(3):877-86.

23- Servatyari K, Yousefi F, Valizadeh Ardalan P, Rasouli MA, Hosseini S, Ghaderi M, Yazdan Panah $\mathrm{H}$, Mardani N. The prevalence of depression and disappointment and their relationship with Substance addiction tendency among high school students in Divandareh City in 2018. Shenakht journal of psychology \& psychiatry. 2019;6(5):1-3. [Persian]

24- Khaledian M, Mohammadifar MA. On the effectiveness of group cognitive-behavioral therapy and logotherapy in reducing depression and increasing life expectancy in drug addicts. Research On Addiction . 2016;9(36):63-80. [Persian]

25- Rezaee N, Navidian A, Moshtaghi E. The effectiveness of life skills training on the level of hope in recovering addicts referring to the Zahedan psychiatric center. Sadra Medical Journal. 2017;5(4):187-98. [Persian]

26- Khaledian M, Yarahmadi M, Mahmoudfakhe H. Effect of group logotherapy in reducing depression and increasing hope in drug addicts. Journal of Research and Health. 2016;6(1):167-74. [Persian]

27- Alami S, Bakhtiarpour S, Asgari P, Seraj-Khorrami N. The Effectiveness of Cognitive-Behavioral Group Therapy and Existential Group Therapy on Anxiety in Addicted Patients Undergoing Methadone Maintenance Treatment. Int J Body Mind Culture. 2020:248-55.

28- Haghighat S, Mohammadi A. Comparison of the Effectiveness of Cognitive Behavioral Therapy and Acceptance and Commitment Therapy on Reducing Mood Symptoms in Patients With Substance Abuse. Int Clin Neurosci J. 2018;5(4):158-63. 